\title{
Enhancing Main Fermentation Velocities in Beer by the Use of a Membrane Bioreactor - Approach and Preliminary Results (Membrane Bioreactor Beer)
}

\section{LISA STUMPF AND STEFAN SCHILDBACH*}

\begin{abstract}
The potential of the most recent membrane technology is still unaccounted for in many respects. Combining fermentation with up-to-date membrane technology building a membrane bioreactor allows the adjustment of the cell count on a high level, increasing yield per volume and time. Applied to beer manufacturing, main fermentation times of less than $20 \mathrm{~h}$ seem possible, avoiding the disadvantages of already known accelerated fermentation processes operated on a continuous basis. Although module design was adapted and backwash procedure altered to gas-jet, maintaining a sufficient membrane flux over time still poses a major problem. Nevertheless, preliminary results in respect of beer quality look promising.
\end{abstract}

Keywords: membrane bioreactor (MBR), beer, main fermentation

\section{Introduction}

Following wort production in the brewhouse, the main and second fermentation of beer takes place in the so called cold block. As the cold block is of a considerable size, high investment costs are required. Hence any shortening in fermentation time leads to proportional downsizing of the fermentation volume and hence to smaller investments, but also cooling capacities and therefore operation costs.

Until now in the brewing industry the state of the art production method is batchwise fermentation. Numerous attempts were made to shorten fermentation times, requiring up-to-date big size tank technology. As a consequence, the overall production time has been cut down from between 20 to 31 days ( 6 to 10 days for main fermentation and 14 to 21 days for second fermentation) to 12 to 19 days nowadays (7 to 12 days combined main and second fermentation and 5 to 7 days cold storage before filtration). Main fermentation takes place within 3 to 4 days.

* Corresponding author. E-mail: stefan.schildbach@lt.hs-fulda.de Hochschule Fulda University of Applied Sciences, Germany 
Further improvements were studied by testing continuously operated fermentations (e.g. Baker et al. 1973, Van de Winkel et al. 1993, Fitzner 1998, Ludwig 2003, Verbelen et al. 2006). In these tests wort from the brewhouse passed a fermenter equipped with immobilised yeast. An overview is given by Branyik et al. (2008). Times for the main fermentation are depending on the type of reactor and reach from $19 \mathrm{~h}$ to $55 \mathrm{~h}$ (Ludwig 2003). Nevertheless, sensory properties are different from beers fermented batchwise and hence do not fully meet consumer's expectations.

Besides ethanol as the major component derived from fermentation, higher alcohols as well as esters are formed. These contribute significantly to the aroma of the final product. Furthermore, the $\mathrm{pH}$ is lowered by one unit during the main fermentation, which results from the yeast releasing organic acids and which is beneficial for beer quality, e.g. in respect to better bitter taste and improvement of the non-biological stability of the beer. These and other changes are directly related to the yeast growth during the first phases of the main fermentation process as they result from the anabolic metabolism. Hence Ludwig (2003) pointed out the relevance of a well-dosed aeration and therefore a controlled yeast growth during continuously operated beer fermentation processes. In his research he was able to significantly improve process stability of a continuous fermentation with immobilised yeast by applying a $\mathrm{pH}$-controlled aeration scheme. Nevertheless, long-term stability was still an issue, which presumably is caused by a non-defined yeast age and cell count in immobilised yeast fermenters. Due to the expected advantages, continuously operated main fermentations are back in the focus and part of recent research (MüllerAuffermann et al. 2013, Meyer 2017), giving the approach new momentum. To take maximum advantage of the approach means to implement the main fermentation into an overall continuously operated brewery, including brewhouse steps like mashing, lautering and wort boiling as well as maturation.

Combining a fermenter with a membrane filtration allows the retention of biomass independently from any carrier material. Therefore, the concentration of the yeast can be adjusted independently from the throughput. Corresponding approaches are well known from aerobic waste water treatment with so called membrane bioreactors (MBR), in which membranes are submerged into the reactor.

Consequently, the main questions for the present project can be summarized as follows: 
- What means are necessary to achieve high flux of the submerged membranes on a permanent base in order to make the process economically attractive?

- Is it possible to decrease main fermentation time from the current 3 to 4 days to $<20 \mathrm{~h}$, or rather to $10-12 \mathrm{~h}$, in a continuously operated, membrane based system by increasing the yeast cell count?

- Is it possible to achieve a beer quality comparable to beers from batchwise fermentations in order to meeting consumer's expectations?

\section{Materials and Methods}

\section{Membranes and modules}

The membrane capillaries (homogeneous, asymmetrical) used for the modules had microfiltration size and were made out of polyethersulfone PES, Type 130403-05-D1 (sourced from MAHLE InnoWa GmbH, Schwaikheim, Germany). Average pore size according to the manufacturer is $0.4 \mu \mathrm{m}$. The bubble point of the wetted membranes was measured using Sartocheck 4 Plus Filter Tester (Sartorius Stedim Biotech, Göttingen, Germany). Based on the bubble point the nominal pore size was calculated according to Formula 1, resulting in $0.24 \mu \mathrm{m}$ pore size.

$$
D=\frac{4 * \sigma * \cos \theta}{p_{B P}}
$$

Formula $1 . \mathrm{D}=$ pore size; $\sigma=$ surface tension (water); $\theta=$ contact angle; $\mathrm{p}_{\mathrm{BP}}=$ bubble point

The size of the capillaries was checked using a digital microscope (VHX-600 from Keyence International NV/SA, Osaka, Japan). Evaluation of the cross section of the capillaries yielded an average of $2.23 \mathrm{~mm}$ outer diameter, an inner diameter of $1.44 \mathrm{~mm}$ and a resulting membrane thickness of $0.40 \mathrm{~mm}$.

Potting of the capillaries was done on-site using epoxy resin Brandopox EPL 101 (Marquardt, Potsdam, Germany) (see Figs 1 and 2). Modules $1^{\text {st }}$ generation showed a higher packing density of $470 \mathrm{~m}^{2} / \mathrm{m}^{3}$. Later the packing density was lowered to $125 \mathrm{~m}^{2} / \mathrm{m}^{3}$ (modules $2^{\text {nd }}$ generation). 
Visualization of the mixing was done using ink Brilliant Schwarz 4001 (Pelikan, Berlin, Germany).

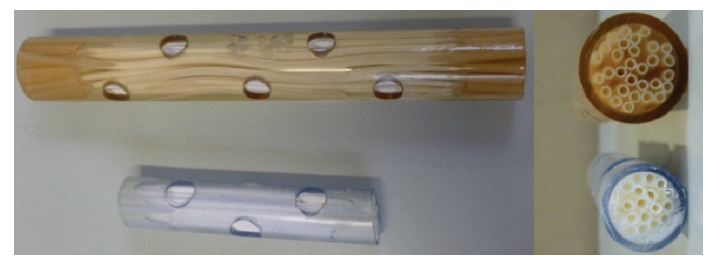

Fig. 1. Test modules $1^{\text {st }}$ generation (high packing density, $470 \mathrm{~m}^{2} / \mathrm{m}^{3}$ )
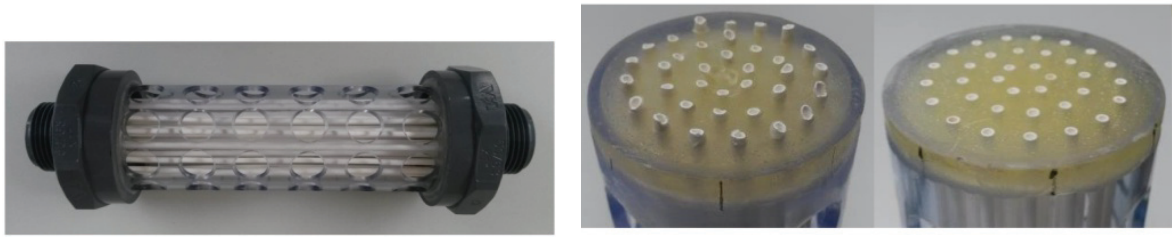

Fig. 2. Potting of the capillaries using epoxy resin, modules $2^{\text {nd }}$ generation with decreased packing density $\left(125 \mathrm{~m}^{2} / \mathrm{m}^{3}\right)$

\section{Operation mode}

At the beginning the procedure consisted of alternating phases of removing green beer from and adding wort in small amounts into the reactor through the membrane. The idea behind this procedure was to keep the membrane free in both directions by reverse liquid streams. Later the operating scheme was changed in such manner, that only green beer was taken from the reactor passing the membrane, whereas the wort was dosed directly into the reactor. Green beer was withdrawn from the reactor using a flexible-hose pump (Heidolph Pumpdrive 5201, Schwabach, Germany).

Wort was obtained from a commercial brewery in Hesse (Germany), commonly used for Pils or Export beer type. Trials were done in a stirred tank reactor (STR) with a maximum size of $8 \mathrm{~L}$, but usually filled with $5 \mathrm{~L}$ only to leave some headspace for foaming. Depending on the trials the reactor was equipped with different types of modules as shown exemplarily in Fig. 3.

The low flocculating yeast strain SMA-S (VLB - Versuchs- und Lehranstalt für Brauerei e.V., Berlin, Germany) from the strain collection from Research and Teaching Institute for Brewing (VLB, Berlin, Germany) was used. The yeasts were stored under cryogenic conditions at $-70^{\circ} \mathrm{C}$ and 
propagated on demand using several propagation steps in order to increase the amount of yeast to inoculate the fermenter. Fermentation temperature was set to $15^{\circ} \mathrm{C}$.

\section{Analytics}

Original gravity, real extract and ethanol concentration were determined by using a beer analyser Anton Paar DMA 4500 density meter coupled with Alcolyzer Beer ME (Anton Paar, Graz, Austria). Volatile aroma compounds (esters and higher alcohols) presented in Table 1 were analysed by Central Laboratory of Research and Teaching Institute for Brewing (VLB, Berlin, Germany). Redox potential was measured inline (SenTix ORP, Weilheim, Germany) and yeast cell count was done using a Thoma chamber after diluting the sample with $0.1 \mathrm{n} \mathrm{NaOH}$ for better dispersion of the cells.

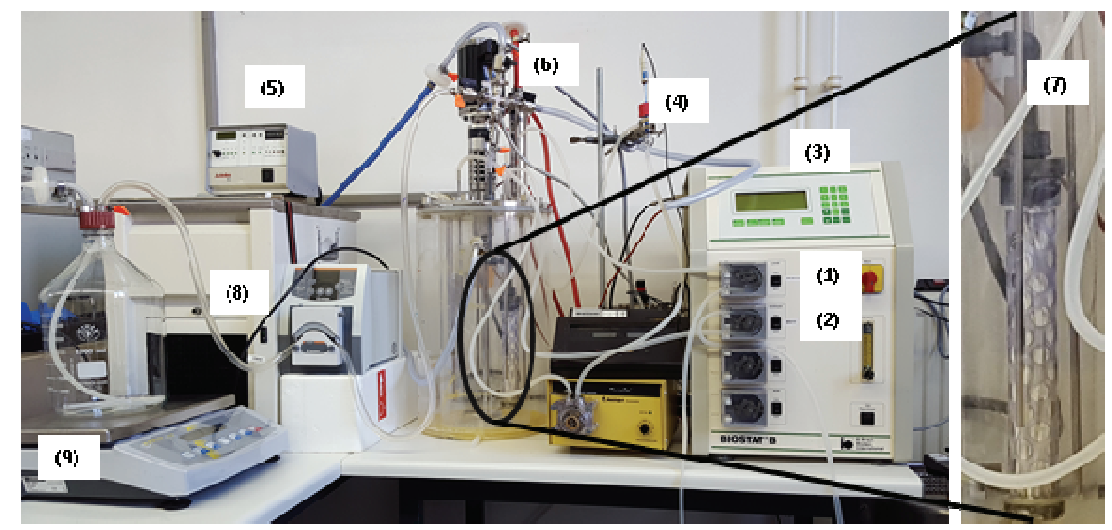

Fig. 3. STR equipped with membrane modules; 1 : wort feeding by flexible-hose pump; 2 : yeast harvest by flexible-hose pump; 3: measuring $\mathrm{pH}$ by control unit Biostat $\mathrm{B}$ (B. Braun, Melsungen, Germany); 4: measuring loop with electrode for redox potential; 5 : cryostat for temperature control; 6: cross splitter (filtrate withdrawal, air-jet, pressure release); 7: submerged filtration module; 8: green beer drain by flexible-hose pump; 9: scale for measuring the amount of green beer; scales for wort and yeast not shown

\section{Results and Discussion}

\section{Module design and operation}

Higher packing density of $470 \mathrm{~m}^{2} / \mathrm{m}^{3}$ (modules $1^{\text {st }}$ generation, refer to Fig. 1) led to problems during operation. The capillaries were flushed 
insufficiently by the surrounding fermentation broth, leading to inhomogeneities of substrate concentration. This was especially problematic when following the first approach of alternating operation routine with wort and green beer being transferred to and from the reactor via the membranes. The whole module acted like a sponge, resulting in huge volumes of mixed phases of wort and green beer, and even thorough purging regimes did not show satisfactory results. As a consequence, the module design was changed, decreasing the packing density to $125 \mathrm{~m}^{2} / \mathrm{m}^{3}$ (modules $2^{\text {nd }}$ generation, refer to Fig. 2). Primary focus was on the equal distribution of the flux over the capillary surface, which was shown in tests using ink (Fig. 4). As the distance between the capillaries was increased, backmixing in dead zones of the modules was minimized.

Nevertheless, accumulation of wort particles within the capillaries and consequently blocking of the inner surface of the membrane capillaries was still an issue. Wort contains a number of particles which is referred to as cold break, consisting mainly of proteins precipitating during wort cooling. Smaller particles of below $1 \mu \mathrm{m}$ interfere with the membrane pores (diameter $0.24 \mu \mathrm{m}$ ). Hence, the alternating operation was substituted by only the green beer being transferred through the membrane, but the wort was added directly into the fermenter.

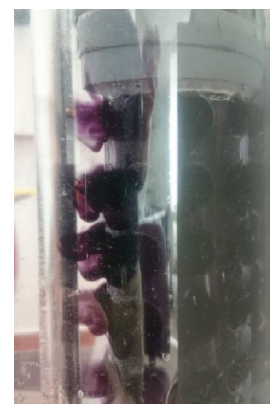

Fig. 4. Flux over membrane surface using black ink for visualisation

As a consequence a different backwash procedure had to be set up. Backwashing with gas - air or carbon dioxide - showed promising results, as can be seen in Fig. 5. One filtration cycle consists of several phases, with phase 1 filtration of green beer, phase 2 interrupting filtration and backwashing with air (air-jet) and phase 3 pausing (neither filtration nor backwashing). Filtration takes place from the outside of the capillaries to the inside (out-in), whereas the backwashing by air is in in-out direction, using air pressure above the bubble point of the membranes (10 s at 4.0 bar). The 
pausing phase is required for letting the foam settle, which is caused by the air-jet. Furthermore the length of the pausing phase provides a setting parameter for the overall green beer withdrawal. No green beer is required for backwashing, so the flux shown is already the net flux.

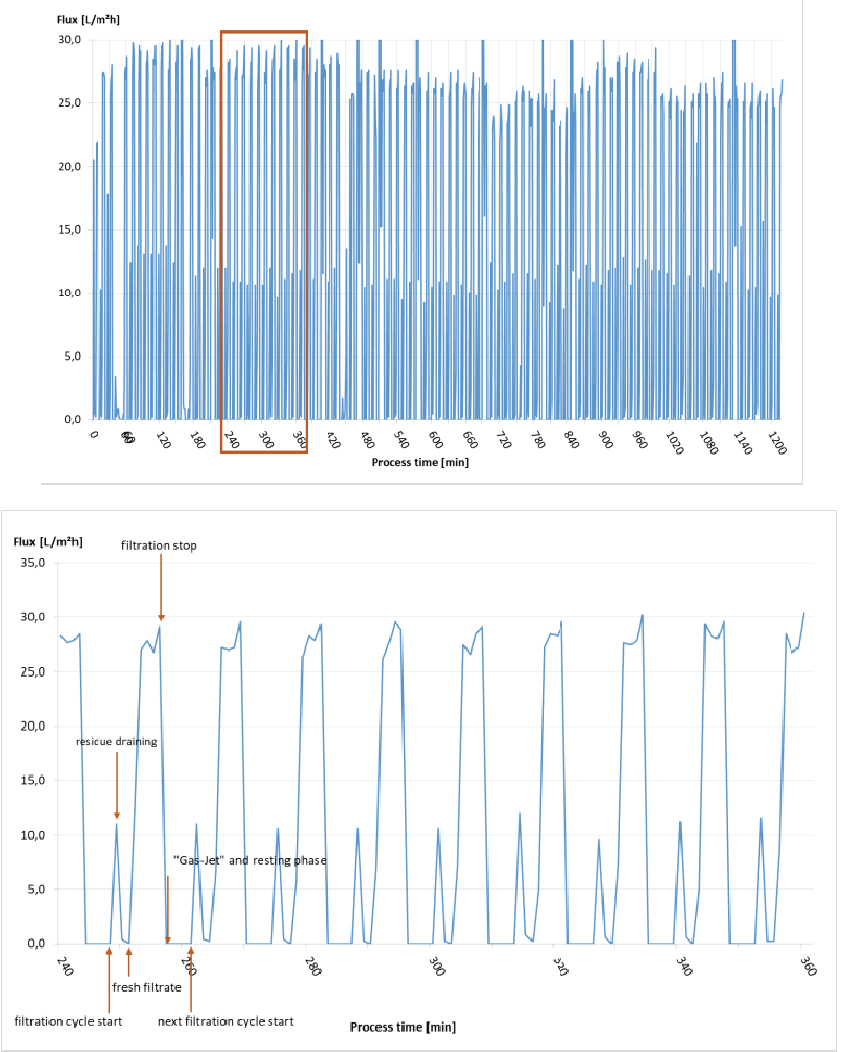

Fig. 5. Flux of green beer with regular backwashing by air-jet; above: filtration flux outin; below: excerpt showing backwash procedure in more detail (filtration step of green beer out-in stops and an air-jet in-out is applied, followed by a pause allowing the foam to settle within the reactor and adapting the overall green beer withdrawal to technological requirements (reaching final attenuation); after the start of the next filtration cycle first residues of green beer from connecting tubes and hoses are transferred to the receiving bottle, which is positioned on a scale to measure the filtrate, by flexible-tube pump)

Flux rates during the filtration phases were kept constant at approx. $25 \mathrm{~L} /\left(\mathrm{m}^{2 *} \mathrm{~h}\right)$. Nevertheless, after $20 \mathrm{~h}$ of operation, one capillary in the module failed mechanically, obviously being too weak for the applied backwash procedure by air-jet (Fig. 6). 
After consultation with the membrane manufacturer, new and more uniform capillaries are available now and will be used in further trials. It is expected that they will show better mechanical durability.

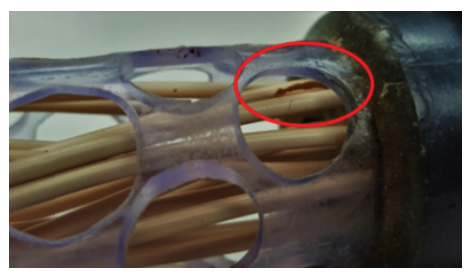

Fig. 6. Broken capillary after air-jet

\section{Technological results}

In a first set of trials yeast cell count was increased and fermentations were done batchwise in order to evaluate the impact on fermentation velocity. Compared to typical yeast cell concentrations during common main fermentation in beer of approx. $60 * 10^{6}$ cells $/ \mathrm{ml}$ the number of yeast cells was increased quite significantly up to more than $300 * 10^{6}$ cells $/ \mathrm{ml}$. The results are shown in Fig. 7.
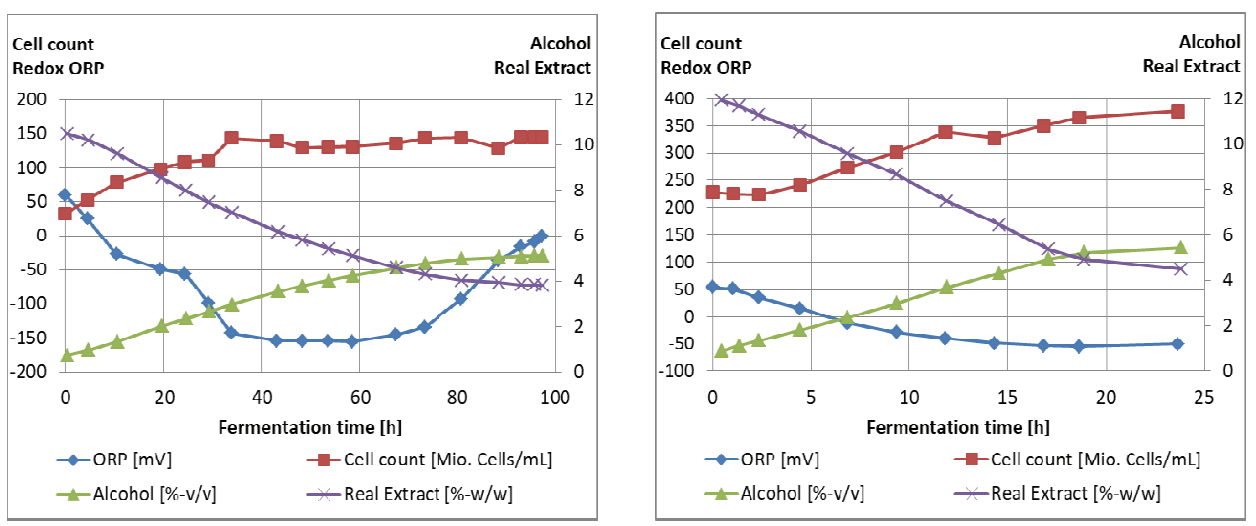

Fig. 7. Fermentations at different yeast cell counts; left: yeast cell count increasing from appr. 40 to $150 * 10^{6}$ cells $/ \mathrm{mL}$; right: yeast cell count increasing from appr. 240 to 370 * $10^{6}$ cells $/ \mathrm{mL}$, resulting in much shorter fermentation time

In Fig. 8 all trials with different yeast cell count are summarized and reveal a linear relationship between yeast cell count and fermentation 
velocity. At a yeast cell count of $>300 * 10^{6}$ cells $/ \mathrm{ml}$ main fermentation time drops below $20 \mathrm{~h}$.

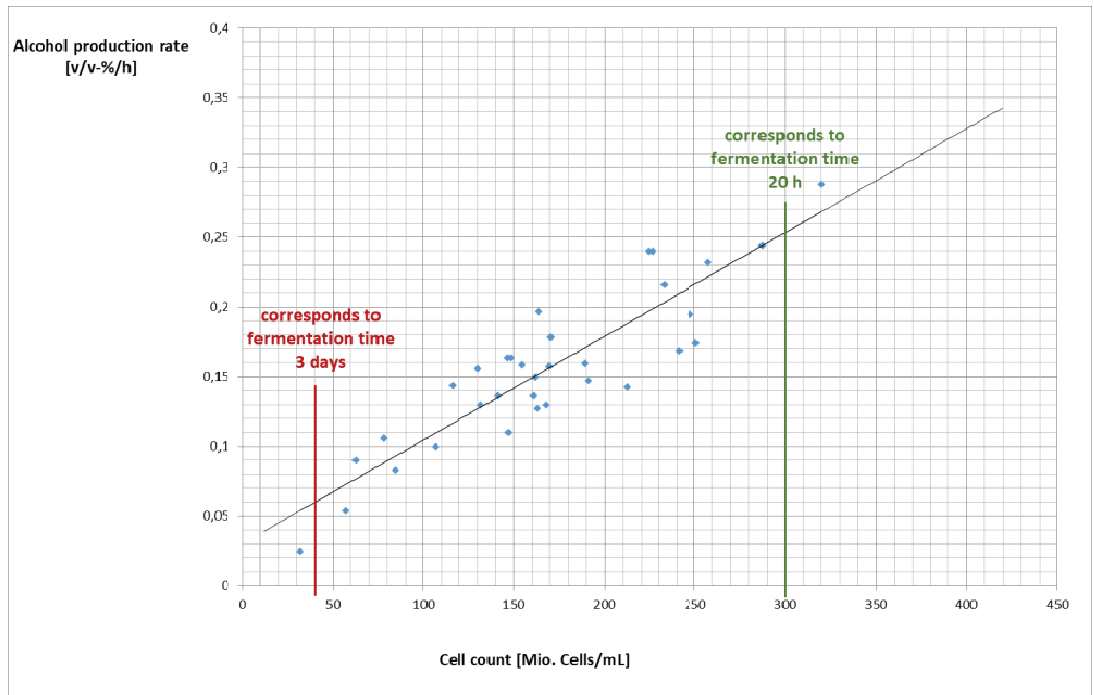

Fig. 8. Fermentation velocity depending on yeast cell count (batchwise fermentation)

Table 1. Analytical data green beer continuous operation

\begin{tabular}{|l|c|l|}
\hline & $\begin{array}{c}\text { Analysis } \\
\text { (mg/L) }\end{array}$ & \multicolumn{1}{|c|}{$\begin{array}{c}\text { Reference values } \\
\text { (Krüger and Anger 1990) } \\
\text { (mg/L) }\end{array}$} \\
\hline Acetaldehyde & 33 & $\mathrm{~N}: 2-10 /$ green beer $>30$ \\
\hline Ethyl acetate & 16 & $\mathrm{~N}: 10-40 / \mathrm{L}: 4-87$ \\
\hline 1-Propanol & 33 & $\mathrm{~N}: 7-16 / \mathrm{L}: 3-48$ \\
\hline Isobutanol & 31 & $\mathrm{~N}: 5-20 / \mathrm{L}: 1,5-84$ \\
\hline Isoamyl acetate & $<0,3$ & $\mathrm{FT}: 1-2$ \\
\hline 2-Methyl-1-butanol & 28 & $\mathrm{~N}: 8-30 / \mathrm{L}: 7-41$ \\
\hline 3-Methyl-1-butanol & 70 & $\mathrm{~N}: 30-70 / \mathrm{L}: 44-123$ \\
\hline 2-Phenylethanol & 33 & $\mathrm{~N}: 8-35 / \mathrm{L}: 0,1-102$ \\
\hline 2-Phenylethyl acetate & $<0,3$ & $\mathrm{~N}:<1$ \\
\hline
\end{tabular}

$\mathrm{N}=$ normal values, $\mathrm{L}=$ limit values; $\mathrm{FT}=$ Flavour threshold 
Transferring the results to continuous operation using membranes, a similar fermentation speed was achieved (results not shown). The corresponding green beer quality concerning esters and higher alcohols are comparable to typical values for green beers produced batchwise (see Table 1). Sensory evaluation did not show any abnormalities. But it has to be pointed that this is only a snap-shot. Due to the short overall operation time, no conclusion regarding the long-term stability of the process is possible at the moment.

\section{Conclusions}

Lowering the packing density helped to avoid concentration gradient forming of wort and green beer within the fermenter. By adapting the backwash regime, especially by using an air-jet as backwash, a filtrate flux of $25 \mathrm{~L} /\left(\mathrm{m}^{2 *} \mathrm{~h}\right)$ was maintained. Nevertheless, after $20 \mathrm{~h}$ of operation time one of the capillaries failed as it could not stand the stress applied by the air-jet. A new generation of membrane capillaries is expected to show better mechanical stress resistance.

From the technological point of view final attenuation can be reached within less than $20 \mathrm{~h}$ of main fermentation time by increasing the yeast cell count to approx. $300 * 10^{6}$ cells $/ \mathrm{mL}$. This was shown by batchwise fermentations performed at different yeast cell counts. Beer quality in respect of the main aroma compounds look comparable, although no longterm data are available at the moment, emphasizing the need for further investigation. To further assess the technological consequences, the MBR has to be operated over a longer period of time. In order to run the process overnight and on weekends, automation is currently underway and will be the basis for further investigations.

\section{Acknowledgement}

Many thanks to Nicolas Werner, Rainer Schmitt and Sebastian Kaiser, who were working on the project in connection with their referring master thesis.

We owe gratitude to Wissenschaftsförderung der Deutschen Brauwirtschaft for financial support. 


\section{References}

Baker, D. A., Kirsop, B. H. (1973) Rapid Beer Production and Conditioning Using a Plug Fermentor. Journal of the Institute of Brewing, 79(6): 487-494

Branyik, T., Vicente, A. A., Dostalek, P., Teixeira, J. A. (2008) A Review of Flavour Formation in Continuous Beer Fermentations. Journal of the Institute of Brewing, 114: 3-13

Fitzner, M. (1998) Der Einsatz immobilisierter Hefen in der Brauerei unter besonderer Berücksichtigung der Angärphase und ausgewählter Reaktortypen und Trägermaterialien (Application of Immobilized Yeast in the Brewery with Special Focus on the Initial Fermentation Phase and Selected Reactor Types and Carrier Materials). Dissertation, Technische Universität Berlin, Fachbereich 15 - Lebensmitteltechnologie

Krüger, E., Anger, H.-M. (1990) Kennzahlen zur Betriebskontrolle und Qualitätsbeschreibung in der Brauwirtschaft (Key Figures for Manufacturing Control and Quality in Brewing Industry). Hamburg, Behr's Verlag

Ludwig, A. (2003) Zur Verbesserung der Langzeitstabilität von Verfahren mit immobilisierter Hefe bei der Hauptgärung (Improvement of Long-term Stability of Main Fermentations with Immobilized Yeasts). Dissertation, Technische Universität Berlin, Fakultät III Prozesswissenschaften

Meyer, B. (2017) Neue Entwicklungen bei der Hefeimmobilisierung (New Developments in Yeast Immobilisation). Brauerei Forum, 8-11

Müller-Auffermann, K., Hutzler, M., Riedl, F., Osnabrügge, M., Caro, M., Jacob, F. (2013) Alternative, Biological Methods in the Flow Profile: Characterization of Bioreactors. BrewingScience, 66

Van de Winkel, L., Van Beveren, P. C., Borremans, E., Goossens, E., Masschelein, C. A. (1993) High Performance Immobilized Yeast Reactor Design for Continuous Beer Fermentation. Oslo: Proceedings of the 24th EBC-Congress: 307-314

Verbelen, P. J., De Schutter, D. P., Delvaux, F., Verstrepen, K. J., Delvaux, F. R. (2006) Immobilized Yeast Cell Systems for Continuous Fermentation Applications. Biotechnology Letters, 28: 1515-1525 